\title{
Molecular adaptation to salinity fluctuation in tropical intertidal environments of a mangrove tree Sonneratia alba
}

\author{
Xiao Feng ${ }^{1 \dagger}$, Shaohua $\mathrm{Xu}^{1 \dagger}$, Jianfang $\mathrm{Li}^{1 \dagger}$, Yuchen Yang ${ }^{1}$, Qipian Chen ${ }^{1}$, Haomin Lyu' ${ }^{1}$ Cairong Zhong ${ }^{2}$,
} Ziwen $\mathrm{He}^{1 *}$ and Suhua Shi ${ }^{1 *}$

\begin{abstract}
Background: Mangroves have adapted to intertidal zones - the interface between terrestrial and marine ecosystems. Various studies have shown adaptive evolution in mangroves at physiological, ecological, and genomic levels. However, these studies paid little attention to gene regulation of salt adaptation by transcriptome profiles.

Results: We sequenced the transcriptomes of Sonneratia alba under low (fresh water), medium (half the seawater salinity), and high salt (seawater salinity) conditions and investigated the underlying transcriptional regulation of salt adaptation. In leaf tissue, $64 \%$ potential salinity-related genes were not differentially expressed when salinity increased from freshwater to medium levels, but became up- or down-regulated when salt concentrations further increased to levels found in sea water, indicating that these genes are well adapted to the medium saline condition. We inferred that both maintenance and regulation of cellular environmental homeostasis are important adaptive processes in $S$. alba. i) The sulfur metabolism as well as flavone and flavonol biosynthesis KEGG pathways were significantly enriched among up-regulated genes in leaves. They are both involved in scavenging ROS or synthesis and accumulation of osmosis-related metabolites in plants. ii) There was a significantly increased percentage of transcription factor-encoding genes among up-regulated transcripts. High expressions of salt tolerance-related TF families were found under high salt conditions. iii) Some genes up-regulated in response to salt treatment showed signs of adaptive evolution at the amino acid level and might contribute to adaptation to fluctuating intertidal environments.
\end{abstract}

Conclusions: This study first elucidates the mechanism of high-salt adaptation in mangroves at the whole-transcriptome level by salt gradient experimental treatments. It reveals that several candidate genes (including salt-related genes, TFencoding genes, and PSGs) and major pathways are involved in adaptation to high-salt environments. Our study also provides a valuable resource for future investigation of adaptive evolution in extreme environments.

Keywords: Homeostasis, Mangrove, Salt adaptation, Sonneratia alba, Transcription factor, Transcriptome profiles

\footnotetext{
* Correspondence: heziwen@mail.sysu.edu.cn; Issssh@mail.sysu.edu.cn

${ }^{+}$Xiao Feng, Shaohua Xu and Jianfang Li contributed equally to this work.

'State Key Laboratory of Biocontrol, Guangdong Key Lab of Plant Resources, Key Laboratory of Biodiversity Dynamics and Conservation of Guangdong Higher Education Institutes, School of Life Sciences, Sun Yat-Sen University, Guangzhou, China

Full list of author information is available at the end of the article
}

(c) The Author(s). 2020 Open Access This article is licensed under a Creative Commons Attribution 4.0 International License, which permits use, sharing, adaptation, distribution and reproduction in any medium or format, as long as you give appropriate credit to the original author(s) and the source, provide a link to the Creative Commons licence, and indicate if changes were made. The images or other third party material in this article are included in the article's Creative Commons licence, unless indicated otherwise in a credit line to the material. If material is not included in the article's Creative Commons licence and your intended use is not permitted by statutory regulation or exceeds the permitted use, you will need to obtain permission directly from the copyright holder. To view a copy of this licence, visit http://creativecommons.org/licenses/by/4.0/. The Creative Commons Public Domain Dedication waiver (http://creativecommons.org/publicdomain/zero/1.0/) applies to the data made available in this article, unless otherwise stated in a credit line to the data. 


\section{Background}

How species adapt to extreme environments is a fundamental topic of evolutionary biology. Located at the interface between terrestrial and marine ecosystems, intertidal zones impose many harsh or extreme conditions on local organisms, including high salinity, hypoxia, salt fluctuations, strong ultraviolet (UV) light, and high temperature [1]. Nevertheless, mangroves have colonized and became well adapted to these habitats, evolving a series of highly specialized traits including salt tolerance, viviparous embryos, aerial roots, and high tannin content [2-4]. Mangroves are a major group of marine halophytes that thrive and complete their life cycles in high-salinity environments that arise due to fluctuating seawater levels. Thus, they are good model systems for investigating adaptive evolution. Indeed, adaptation in this group has been studied at the phenotypic, ecological, physiological, and genomic levels [5-10]. However, little attention has been paid to transcriptional regulation even though it has been strongly selected for rapid adaptation to changes in environmental conditions and may play a critical role at ecological and evolutionary timescales [11].

Salt adaptation is a long-term and dynamic process brought about by multiple genes involved in many morphological, physiological, molecular, and cellular processes [12-14]. Various salt-responsive genes and important signaling pathways have been identified by global gene profiling in the model plant Arabidopsis thaliana [12, 15], and crop plants rice [16] and soybean [17]. The Salt overly sensitive (SOS) signaling pathway, $\mathrm{Ca}^{2+}$-dependent signaling pathways, and ABA signaling pathways contribute to mediating cellular signaling under salt stress and maintain cellular environmental homeostasis [18]. Many molecular mechanisms have been revealed in glycophytes, but the major limiting factor is their inability to survive high and fluctuating salinity. These studies are insufficient to understand molecular aspects of plant salt adaptation.

Sonneratia alba inhabits low intertidal zones of downstream estuarine systems and is one of the most pervasive and salt tolerant mangrove species. It reaches an optimal growth in 5 to $50 \%$ seawater, indicating its capacity to tolerate high salinity and hypoxia [19]. It can synthesize organic solutes to adjust cellular osmotic potential and produce antioxidant enzymes for scavenging reactive oxygen species (ROS) against high salinity [20]. Therefore, it is an attractive ecological model to investigate genetic mechanisms underlying salt adaptation. However, only limited RNA-seq data from Sonneratia have been reported to date [21, 22]. The lack of transcriptomic information for $S$. alba across salinity conditions is a major obstacle to discerning the molecular bases of adaptation to saline environments. In this study, we designed an experiment to elucidate the transcriptional regulation of high-salt adaptation in $S$. alba. We sequenced transcriptomes from leaves and roots of $S$. alba seedlings irrigated with artificial seawater. After genome-guided transcriptome assembly, we characterized the transcriptomes under low, medium, and high salinity conditions for further functional analyses. We wish to gain new insights into the potential genetic, biochemical, and physiological mechanisms of salt adaptation in $S$. alba. Our study also generates valuable resources to support further research into adaptive evolution of mangroves in extreme environments.

\section{Results}

\section{Identification of differentially expressed genes and expression patterns}

To generate genomic resources and begin elucidating the mechanisms of salt tolerance in $S$. alba, we performed RNA-seq experiments on leaves and roots from plants reared in media with various salt levels. The read summary statistics and assembly results are outlined in Table 1 . We generated 44.20 to 61.97 million of $100 \mathrm{bp}$ paired-end reads from 12 libraries. After quality filtering (see Methods for details) we retained 41.94 to 59.21 million $99 \mathrm{bp}$ high quality reads and successfully mapped 93.85 to $94.83 \%$ of them to the $S$. alba reference genome. These aligned reads were assembled separately within each sample, yielding 33,930 to 40,937 transcripts with average lengths 3298 to $3530 \mathrm{bp}$ and N50 values of 4214 to $4437 \mathrm{bp}$ (Table 1 ). The correlation coefficients between biological replicates in each condition were from 0.87 to 0.97 (Additional file 1: Figure S1).

For $S$. alba, its adaptation to the intertidal zone environment is a long-term and dynamic process, and its growth environment is 5 to $50 \%$ seawater concentration, that is, $25 \mathrm{mM}$ to $250 \mathrm{mM}$ [19]. Hence, $500 \mathrm{mM}$ and 0 $\mathrm{mM}$ provide the hyper-saline (stressful) and low-saline conditions, respectively. A large number of genes between 0 vs 250 are expected to have similar expression levels. The stress would be between $250 \mathrm{mM}$ and 500 $\mathrm{mM}$. We next performed two pair-wise comparisons of transcript abundance: low $(0 \mathrm{mM})$ vs medium $(250 \mathrm{mM})$, and medium vs high $(500 \mathrm{mM})$ salt concentrations (see Methods for details). In the low to medium $\mathrm{NaCl}$ comparison, we found 387 significantly up-regulated and 726 down-regulated genes in leaves, and 169 up- and 295 down-regulated transcripts in roots. We found 1057 up- and 1296 down-regulated genes in leaves, and 247 up- and 133 down-regulated transcripts in roots when comparing the medium and high salt conditions (Fig. 1). There were clearly more differentially expressed genes (DEGs) in leaves than in roots. Moreover, we found more up-regulated genes in the medium to high salt contrast than in the low to medium comparison.

To identify co-expression patterns among the DEGs, we clustered them into eight groups according to their 
Table 1 Summary of mapping and assembly statistics of the Sonneratia alba transcriptomes

\begin{tabular}{|c|c|c|c|c|c|c|c|c|c|c|}
\hline \multirow[t]{2}{*}{ Sample } & \multirow[t]{2}{*}{ Replicate } & \multicolumn{2}{|c|}{ Mapping to genome } & \multicolumn{2}{|l|}{ Multiple mapped } & \multicolumn{2}{|c|}{ Uniquely mapped } & \multirow{2}{*}{$\begin{array}{l}\text { Number of } \\
\text { transcripts }\end{array}$} & \multirow{2}{*}{$\begin{array}{l}\text { Average } \\
\text { size (bp) }\end{array}$} & \multirow{2}{*}{$\begin{array}{l}\text { N50 } \\
\text { (bp) }\end{array}$} \\
\hline & & Number $\left(\times 10^{6}\right)$ & $\%$ & Number $\left(\times 10^{6}\right)$ & $\%$ & Number $\left(\times 10^{6}\right)$ & $\%$ & & & \\
\hline \multirow[t]{2}{*}{ LO } & $r 1$ & 52.26 & 94.59 & 0.44 & 0.84 & 51.82 & 99.16 & 36,664 & 3395 & 4301 \\
\hline & $\mathrm{r} 2$ & 42.27 & 94.12 & 0.64 & 1.51 & 41.64 & 98.49 & 35,970 & 3378 & 4235 \\
\hline \multirow[t]{2}{*}{ L250 } & $r 1$ & 39.85 & 94.02 & 0.42 & 1.05 & 39.43 & 98.95 & 33,930 & 3318 & 4214 \\
\hline & $r 2$ & 39.36 & 93.85 & 0.61 & 1.54 & 38.75 & 98.46 & 35,402 & 3394 & 4273 \\
\hline \multirow[t]{2}{*}{ L500 } & $r 1$ & 55.66 & 94.01 & 0.59 & 1.06 & 55.08 & 98.94 & 34,116 & 3298 & 4221 \\
\hline & $r 2$ & 43.41 & 93.99 & 0.87 & 2.01 & 42.54 & 97.99 & 34,334 & 3443 & 4338 \\
\hline \multirow[t]{2}{*}{ RO } & $r 1$ & 45.47 & 93.97 & 0.49 & 1.09 & 44.97 & 98.91 & 40,937 & 3471 & 4352 \\
\hline & $r 2$ & 43.01 & 94.43 & 1.92 & 4.47 & 41.08 & 95.53 & 40,005 & 3469 & 4380 \\
\hline \multirow[t]{2}{*}{ R250 } & $r 1$ & 44.20 & 94.48 & 0.49 & 1.12 & 43.71 & 98.88 & 40,696 & 3425 & 4363 \\
\hline & $r 2$ & 40.78 & 94.58 & 1.99 & 4.88 & 38.79 & 95.12 & 40,483 & 3476 & 4383 \\
\hline \multirow[t]{2}{*}{ R500 } & $r 1$ & 52.23 & 94.58 & 0.77 & 1.47 & 51.46 & 98.53 & 40,338 & 3530 & 4437 \\
\hline & $r 2$ & 40.63 & 94.83 & 1.13 & 2.79 & 39.49 & 97.21 & 39,426 & 3503 & 4391 \\
\hline
\end{tabular}

$\mathrm{L}$ and $\mathrm{R}$ represent leaf and root tissues; 0, 250 and 500 represent the salinity treatments (mM NaCl); $r 1$ and $\mathrm{r} 2$ indicate two biological replicates with three individuals each. For each sample, RNA-seq reads mapping and genome-guided transcriptome assembly were performed individually

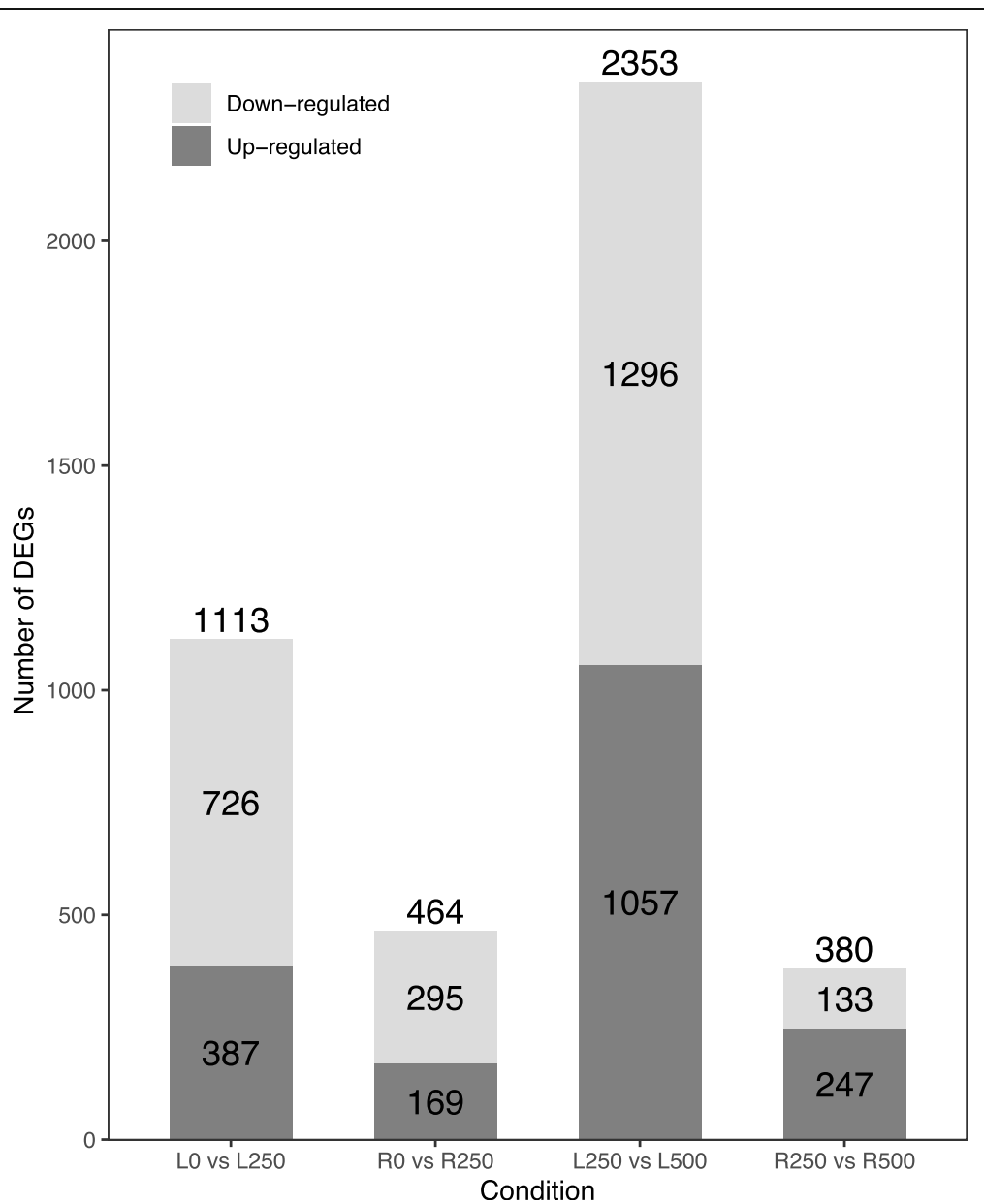

Fig. 1 Differentially expressed genes (DEGs). The number of up- and down-regulated genes in leaves and roots across salinity conditions (0 mM vs $250 \mathrm{mM} \mathrm{NaCl}$ and $250 \mathrm{mM}$ vs $500 \mathrm{mM} \mathrm{NaCl}$ ) is shown. The total number of DEGs is listed on top of each bar 

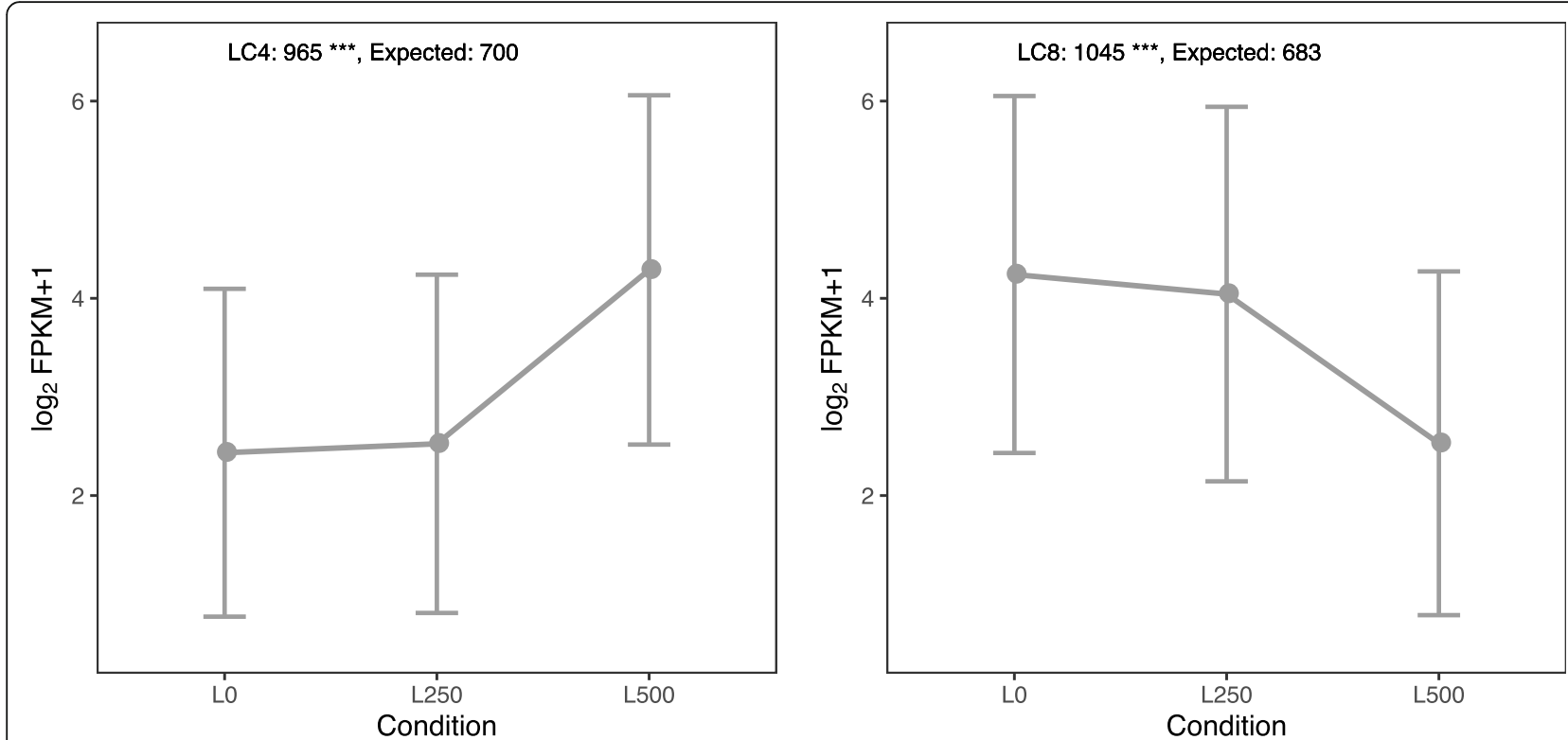

Fig. 2 Significant expression clusters in leaves. The lines represent mean expression levels (means of $\log _{2}(F P K M$ value +1$)$ ) of all genes in a cluster. The error bars represent the standard deviation. The observed and expected numbers of genes belonging to each cluster are labeled on the top of each graph. A permutation test was used to evaluate the significance of differences. The clusters with statistically significant difference in the number of DEGs are marked with triple $(P$-value $<0.01)$ asterisks

expression change across salinity conditions and tissues (Additional file 2: Figure S2). Intriguingly, the two largest leaf clusters, LC8 (1045 genes) and LC4 (965 genes), comprised only genes that are significantly down- or upregulated under high salt treatment (Fig. 2). The same pattern did not hold in the roots, however. To assess whether the LC8 and LC4 clusters are larger than expected by chance, we conducted a permutation test (see Methods for details). We indeed saw that these clusters were larger than expected (Fig. 2). The most genes didn't differentially express across salinity conditions. The LC4 and LC8 are majority (64\%) of all eight clusters. They are only differentially expressed when the salt levels become high $(500 \mathrm{mM})$, but are unchanged in the medium to low $\mathrm{NaCl}$ comparison. Thus, only the extremely high levels of salt treatment were able to appreciably change the $S$. alba transcriptome, as expected given the high salinity tolerance of this species.

\section{Functional enrichment and transcriptional regulation}

We assigned functional Gene Ontology (GO) categories to the DEGs we identified (Additional file 3: Table S1) and four major co-expression clusters, including LC4, LC8, LC4-RC4 (overlaps between LC4 and RC4), LC8RC8 (Additional file 4: Table S2). Using a whole-genome annotation as the background, we found several categories that were over-represented among our differentially expressed genes (Fig. 3). Remarkably, many of the genes up-regulated in leaves were involved in the molecular function category "transporter activity." The biological process category "response to stimulus" was significantly overrepresented in all four comparisons (both leaves and roots). Furthermore, many up-regulated genes were assigned to the "response to stimulus" category in four comparisons (57 in L0 vs L250, 35 in R0 vs R250, 158 in L250 vs L500, 36 in R250 vs R500). Detailed annotations were also performed across up-regulated genes. We note that many genes were annotated with functions involving salt tolerance, especially Sodium/hydrogen exchanger (NHX) encoding gene (SA_23236 in L0 vs L250 and L250 vs L500, SA_23120 in R250 vs R500), Tonoplast intrinsic protein (TIP) encoding gene (SA_14179 in L250 vs L500), Plasma membrane intrinsic protein (PIP) encoding gene (SA_25431 in L0 vs L250 and L250 vs L500, $S A \_09545$ in L0 vs L250, SA_08276, SA_20957, SA_ 24093, SA_26218, SA_26346 in L250 vs L500), Mangrin (SA_08086, SA_14631 in L250 vs L500), several heat shock protein encoding genes, and main transcription factor encoding genes (described in the following section). Mangrin is partially homologous to the allene oxide cyclase (AOC) encoding gene. Several genes upregulated under high salt directly adjust cellular osmotic potential or integrate metabolic, hormonal, and environmental signals in stress acclimatization. They include the glutathione peroxidase encoding gene (SA_08946 in roots and $S A \_18901$ in leaves), the monodehydroascorbate reductase encoding gene ( $S A \_20647$ in leaves), the aldo-keto reductase encoding gene (SA_02762 in both tissues, SA_02758, SA_02759 in leaves, and $S A \_15935$ in roots), a number of key enzymes in biosynthesis of 


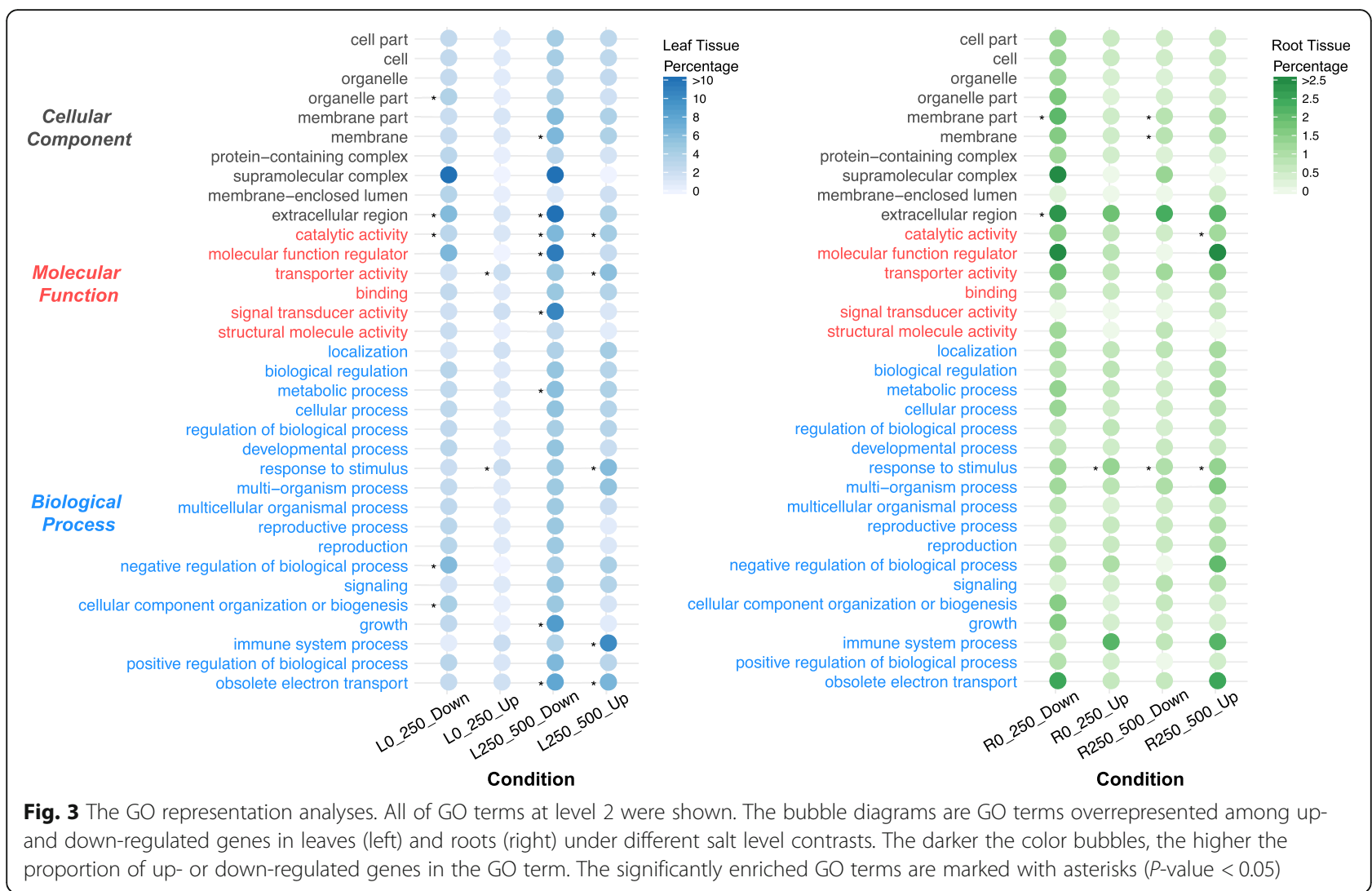

asparagine, cysteine, galactinol, trehalose-6-phosphate, and stachyose. We also found up-regulated transcripts of unknown function. These can be further investigated to gain fresh insights in into salt adaptation.

Interestingly, 965 of the transcripts up-regulated in leaves fall into the LC4 cluster, as do $89.24 \%$ of the 158 genes that were both up-regulated and assigned to the "response to stimulus" GO category (Additional file 4: Table S2). This suggests that this cluster plays an important role in response to abnormally high salt stress.

The GO terms significantly enriched among downregulated genes were "extracellular region" and "catalytic activity" categories in leaves and "membrane part" in roots (Fig. 3). Furthermore, 1045 of transcripts down-regulated in leaves fall into the LC8 cluster, were enriched in categories of "carbohydrate metabolic process", "cell periphery", "negative regulation of molecular function", "catalytic activity" and so on (Additional file 4: Table S2). They were closely associated with basic metabolism, plant growth regulation, molecular function regulator, signal transducer activity, and electron transport.

We next investigated metabolic pathways significantly enriched among the DEGs by cross-referencing our list of up-regulated genes with the KEGG annotation of the $S$. alba reference genome (Additional file 5: Table S3). Of the metabolic pathways overrepresented among transcripts differentially expressed under high salt (four highly and three slightly enriched, Table 2), sulfur metabolism, protein processing in endoplasmic reticulum, and flavone and flavonol biosynthesis were the most interesting because they are known to be involved in $S$. alba salt adaptation. Flavonoid biosynthesis, nicotinate, and nicotinamide metabolism pathways were also overrepresented among genes up-regulated under high salt treatment in roots (Table 2). No metabolic pathways stood out among genes differentially expressed under the medium compared to low salt conditions.

To further explore the regulation of biological pathways under salt treatment, we visualized the expression profiles of up-regulated genes in transcripts assigned to major pathways (Fig. 4). The highlighted pathways are involved in reactive oxygen species (ROS) scavenging, detoxification, and regulation of cell osmotic pressure. We reason that these pathways play essential roles in salt adaptation. Notably, these functional enrichment analyses of DEGs point to the cellular environment as the possible site of molecular salt adaptation in S. alba. This seems plausible as changes in candidate proteins occur within cells.

\section{Transcription factors involved in salt adaptation}

Transcription factors (TFs) are regulatory proteins and therefore have the potential to regulate multiple aspects 
Table 2 KEGG pathways significantly enriched among up-regulated genes in leaves and roots (250 mM vs 500 mM)

\begin{tabular}{|c|c|c|c|c|c|c|}
\hline Condition & Pathway ID & Pathway & $\begin{array}{l}\text { No. of genes } \\
\text { in genome }\end{array}$ & $\begin{array}{l}\text { No. of } \\
\text { up-regulated } \\
\text { genes }\end{array}$ & $P$ value & Adjusted $P$ value \\
\hline \multirow[t]{7}{*}{ Leaf } & ko00920 & Sulfur metabolism & 121 & 19 & $7.12 \mathrm{E}-08$ & $1.58 \mathrm{E}-05$ \\
\hline & ko04141 & Protein processing in endoplasmic reticulum & 605 & 46 & $2.41 \mathrm{E}-06$ & 1.79E-04 \\
\hline & ko04626 & Plant-pathogen interaction & 1253 & 74 & $3.61 \mathrm{E}-05$ & 2.01E-03 \\
\hline & ko00944 & Flavone and flavonol biosynthesis & 101 & 13 & 7.10E-05 & $3.15 \mathrm{E}-03$ \\
\hline & ko00592 & alpha-Linolenic acid metabolism & 95 & 10 & $2.28 \mathrm{E}-03$ & $6.32 \mathrm{E}-02$ \\
\hline & ko00760 & Nicotinate and nicotinamide metabolism & 53 & 7 & 2.84E-03 & 7.01E-02 \\
\hline & ko00270 & Cysteine and methionine metabolism & 312 & 22 & $3.13 \mathrm{E}-03$ & $6.96 \mathrm{E}-02$ \\
\hline \multirow[t]{2}{*}{ Root } & ko00941 & Flavonoid biosynthesis & 85 & 5 & $7.78 \mathrm{E}-04$ & 9.80E-02 \\
\hline & ko00760 & Nicotinate and nicotinamide metabolism & 53 & 4 & $1.05 \mathrm{E}-03$ & $6.60 \mathrm{E}-02$ \\
\hline
\end{tabular}

of salt adaptation by influencing several downstream factors. Previous studies have revealed that TFs perform important functions in abiotic stress response and adaptation [23-27]. Intriguingly, we found more transcription factors, as a proportion of all annotated genes, in $S$. alba $(2595,8.86 \%)$ and S. caseolaris $(2729,9.72 \%)$ than in their inland relatives $P$. granatum $(1847,6.34 \%)$ and E. grandis $(2185,6.01 \%)$. Further, TF encoding genes were overrepresented among the differentially expressed genes identified in all contrasts we performed, but particularly in leaves. The pattern of up-regulated TFs was significant in three comparisons: both leaf contrasts and the low vs medium $\mathrm{NaCl}$ in roots, and several downregulated TFs slightly enriched in the comparison between medium and hyper saline conditions in roots (Fig. 5). Separating transcription factors into generally recognized families (Additional file 6: Figure S3), we found that the AP2/EREBP, NAC, WRKY, and $b Z I P$ families were enriched among the up-regulated genes.

\section{Positive selection in up-regulated genes}

Unusual salt tolerance is a derived characteristic of mangroves. The $\mathrm{Ka} / \mathrm{Ks}$ values along $S$. alba and its relatives were calculated (Additional file 7: Figure S4). It showed that $\mathrm{Ka} / \mathrm{Ks}$ ratio was elevated in the $S$. alba relative to relatives. We would therefore expect that some of the genes up-regulated in response to $\mathrm{NaCl}$ treatment have acquired their roles recently in evolutionary time. We wondered if their amino acid composition changed along with expression level. To test this idea, we used the PAML package to identify positively selected genes (PSGs) in S. alba (see Methods for details). We identified sixteen up-regulated PSGs (Additional file 8: Table S4). The SA_12151 locus has particularly high $\mathrm{Ka} / \mathrm{Ks}$ ratio $(\mathrm{Ka} / \mathrm{Ks}=4.42)$ and has probably undergone positive selection. Functional annotation gives us further confidence that these proteins are relevant to salinity resistance.
Real-time quantitative PCR (qPCR) DEG verification

To assess the reliability of RNA sequencing for DEG identification, transcripts of 16 genes from each cluster were evaluated by qPCR. The expression patterns of selected genes were consistent with the RNA-seq data in eight clusters from both leaves and roots. The results of qPCR are shown in Fig. 6a. The correlation between the $\log _{2}$ fold change of expression level from the RNA-seq experiments and qPCR is shown in Fig. 6b. Correlation between these methods is strong and positive $\left(\mathrm{R}^{2}=0.88\right.$, $P$-value $<1 \mathrm{E}-10)$, suggesting that RNA-seq results are highly reproducible.

\section{Discussion}

Comparative genomics has been extensively used to investigate the genetic bases of adaptation to extreme environments $[6,7,9,10,14,28-31]$. In this study, comprehensive transcriptome analyses from leaves and roots of $S$. alba across salinity conditions were performed to probe the genetic mechanisms underlying salt adaptation. Our results yielded candidate genes and mechanistic hypotheses that may deepen our understanding of salt adaptation in halophytes and provide a resource for further studies.

Salt adaptation is both a long-term and dynamic process influenced by multiple genes and involves many morphological, physiological, molecular, and cellular processes [12, 14, 32-34]. The requirement of bulk protein synthesis as part of the global defense strategy of Arabidopsis has been extensively shown in previous studies [35]. In Zostera marina, which experiences the full marine seawater, $\mathrm{Na}^{+}$and $\mathrm{K}^{+}$antiporters were displayed as a typical component. The salt-tolerant $\mathrm{H}^{+}$ATPase plays an important role in maintaining the low $\mathrm{Na}^{+}$concentration in the seagrass cells since it is strongly expressed in vegetative tissue $[36,37]$. And nitrate assimilation and ion compartmentalization are also required in the process of adaptation [38]. While mangroves induce genes that function in specific saltresponsive pathways and transcription factors that 


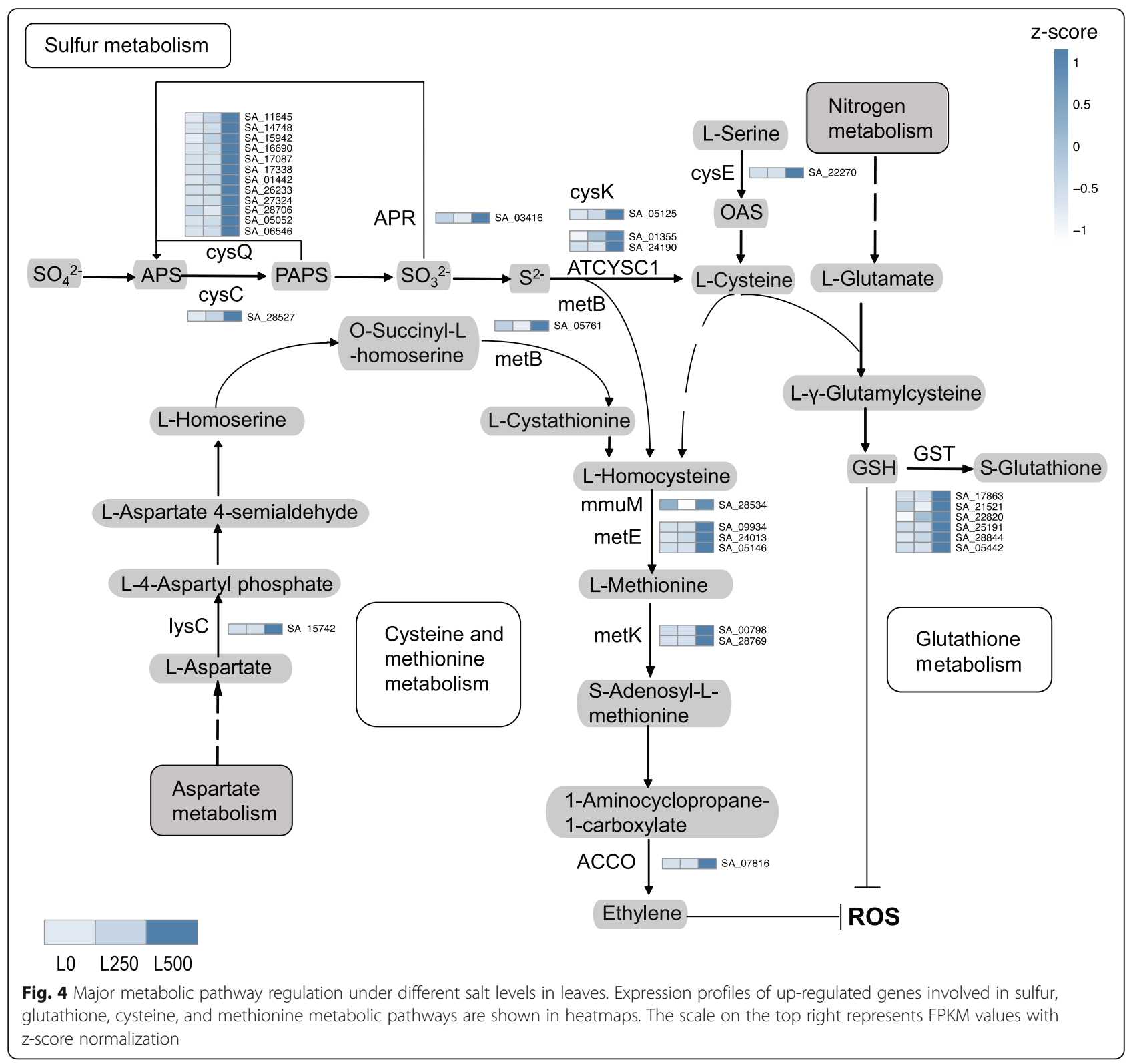

influence the cellular environment. Most genes differentially expressed across salt levels in our study were induced or suppressed by the highest salt concentration in leaves. The pattern is different in roots, suggesting that salt adaptation in $S$. alba is tissue-specific.

A major group of up-regulated genes identified in our study were involved in ion transportation and osmotic regulation, including NHX, TIP, PIP, Mangrin. These genes have been reported to play major roles in salt tolerance in a variety of plants [39-42]. Particularly, Mangrin is partially homologous to the allene oxide cyclase (AOC) encoding gene. It is up-regulated by high salinity and its overexpression enhances salt tolerance in transgenic yeast and tobacco cells [39]. Most transcripts down-regulated under high salt conditions were involved in basic metabolism, plant growth regulation, molecular function regulator, signal transducer activity, and electron transport. This suggests that the long-term high salt treatment might suppress normal metabolic processes and throw off the plant homeostatic balance. Indeed, high salinity is an important agricultural contamination that result in damage to the plant [43]. In Arabidopsis, salt stress does not simply decrease the steady-state growth rates. While the growth of several discrete phases was strongly suppressed by salt stress, the others were actually increased [44].

Hypersaline stress always leads to secondary oxidation stress, resulting in reactive oxygen species accumulation. We indeed observed that a number of key enzymes (such as cysQ, ATCYSC1, cysK, GST) involved in sulfur, 


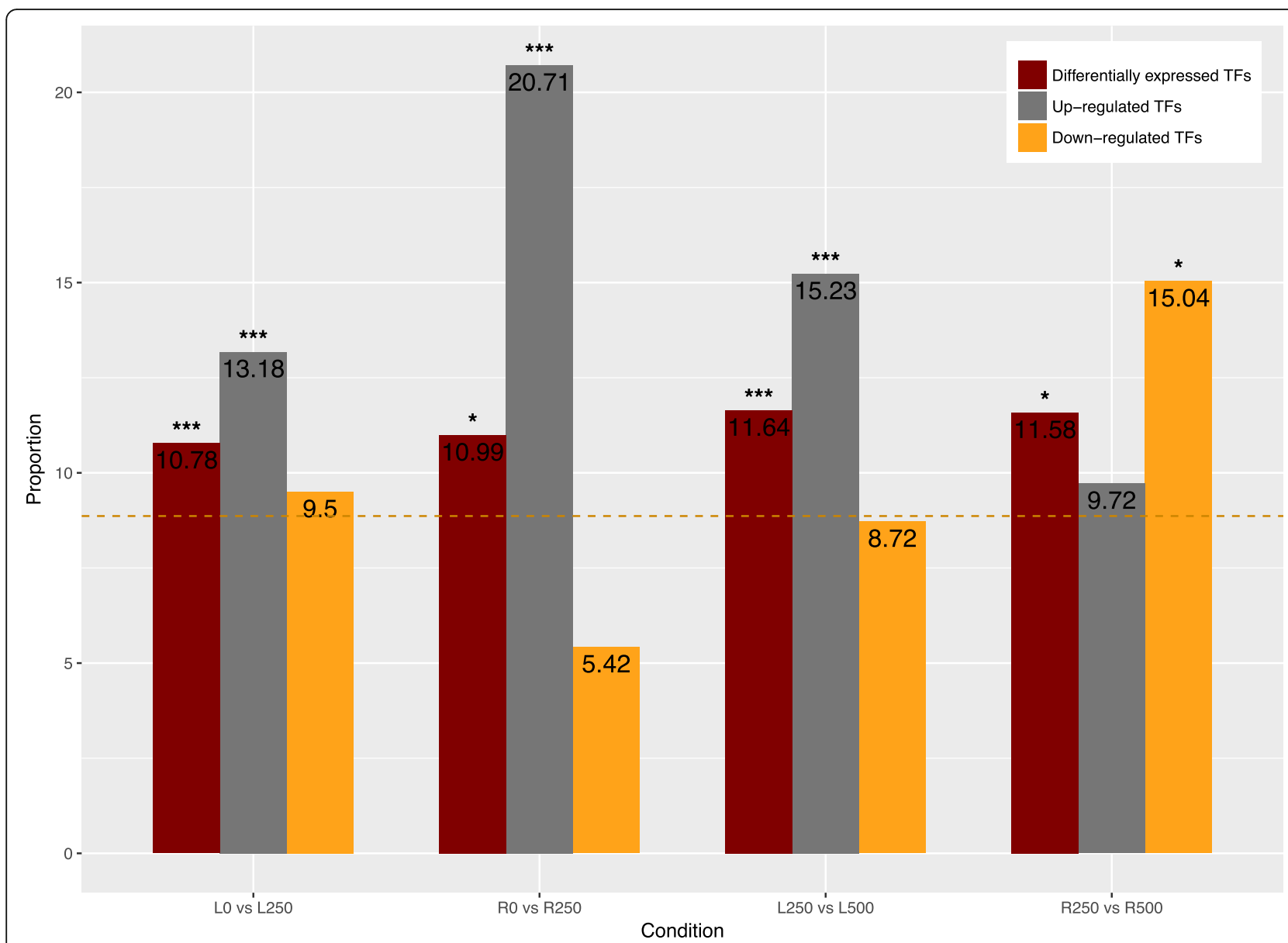

Fig. 5 The proportions of differentially expressed transcription factor encoding genes in leaves and roots under different salinity contrasts ( $0 \mathrm{mM}$ vs $250 \mathrm{mM} \mathrm{NaCl}$ and $250 \mathrm{mM}$ vs $500 \mathrm{mM} \mathrm{NaCl}$ ). Orange dashed line represents the proportion of transcription factor encoding genes in the whole S. alba genome. Red bars represent the proportion of differentially expressed TFs among all DEGs. Gray bars represent the proportion of TFs among up-regulated genes. Orange bars represent the proportion of TFs among down-regulated genes. Fisher's exact test was used to evaluate the significance of the differences between the proportions of differential expressed / up-regulated / down-regulated transcription factors and transcription factor encoding genes in the whole genome. $P$-value ranges are denoted with single (corrected $P$-value $<0.1)$ or triple (corrected $P$-value $<0.05$ ) asterisks

cysteine and methionine, and glutathione metabolism were up-regulated in leaves (Fig. 4). These pathways enhance synthesis of sulfur-rich peptides (such as SGlutathione) to scavenge ROS [45]. In addition, we found that flavone and flavonol biosynthesis pathway genes were overrepresented in our set of differentially expressed transcripts. Flavonoids are natural antioxidants that can reduce ROS levels and aid in survival and growth of plants [46].

Recycling of nicotinamide and nicotinate for pyridine nucleotide synthesis can be stimulated by salt to protect pyrimidine and purine derivatives for nucleotide synthesis in the mangrove Bruguiera sexangula [47]. We also found that genes from the nicotinate and nicotinamide metabolism pathways were overrepresented among transcripts differentially expressed under high salt treatment in both leaves and roots.
Ethylene signalling also influences the response to salt stress in Arabidopsis. High salinity induces the accumulation and activation of EIN3/EIL1 protein. The activated EIN3 alleviates the accumulation of excess ROS accumulation and therefore increases salt tolerance of the plant [48]. We found that key enzymes in the cysteine and methionine, as well as glutathione, metabolism pathways were up-regulated under salt treatment in leaves but not roots. This suggests that ethylene and glutathione are preferentially synthesized in leaf tissue and play a role in long-term salt adaptation.

Several studies have demonstrated that transcription factors act as regulators of adaptation in plants. The functions of certain TFs (such as AP2/EREBP, NAC) in response to salt tolerance in particular have been well documented [35, 49-51]. We also observed that many TF encoding genes were up-regulated under increasing 


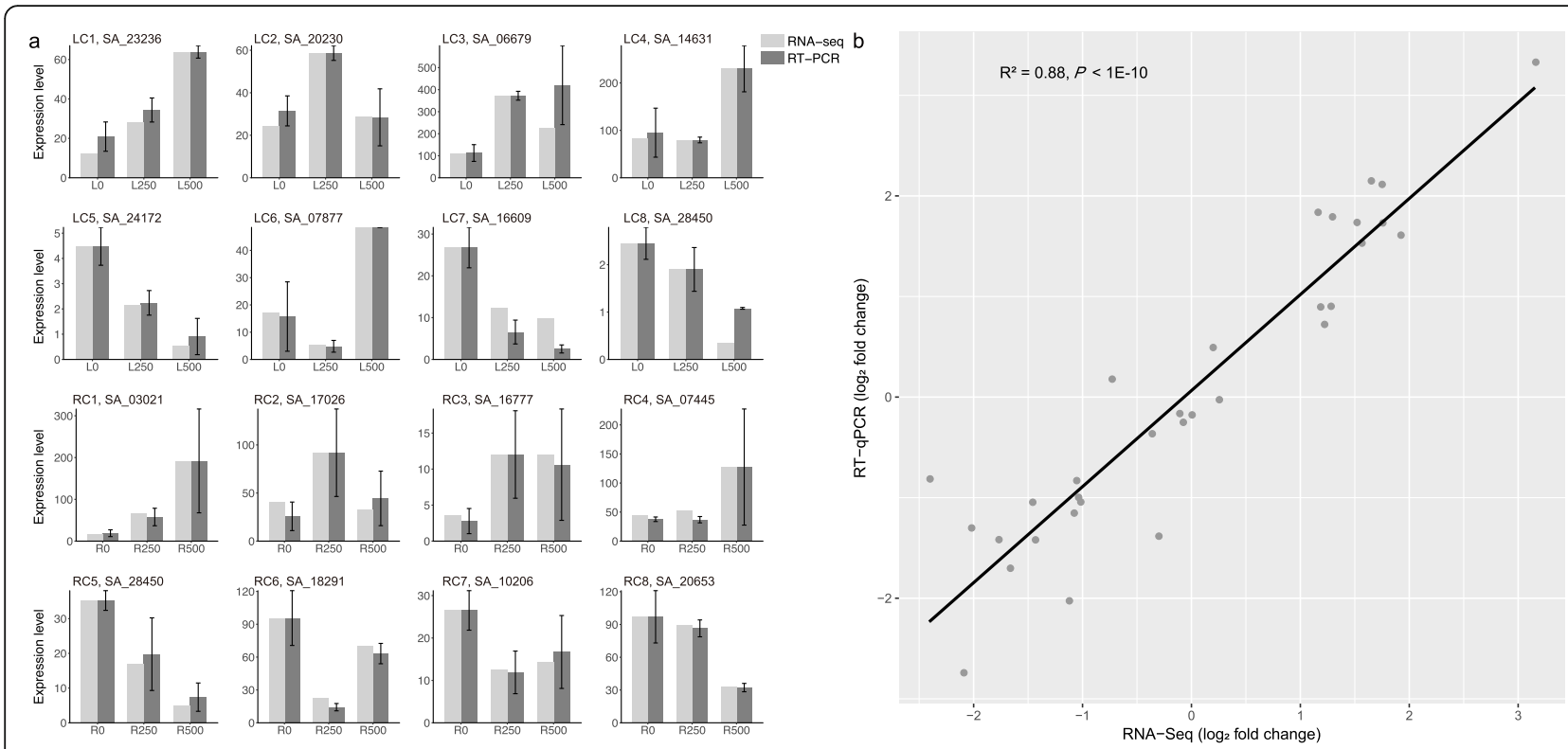

Fig. 6 Validation of RNA-seq results by RT-qPCR. a Transcript levels of 16 genes in the three samples were detected by RT-PCR. Light grey bars indicate transcript abundance changes estimated from RNA-seq. Dark grey bars with associated standard deviations represent the normalized relative expression levels determined by real-time quantitative PCR using the $2^{-\Delta \Delta C T}$ method. $\mathbf{b}$ Correlation of gene expression levels between RNA-seq and RT-qPCR data

salt concentration. Transcription factors of $A P 2 / E R E B P$, WRKY, bZIP, NAC, MYB and bHLH regulate downstream factors to involve in the major pathways, such as flavonoid biosynthesis, sulfur and glucosinolate metabolism [52-57]. This result confirms the GO enrichment and pathway enrichment analyses and shows an extensive regulation of transcription during salt adaptation. However, further investigations are required to find the exact regulatory networks of salt response in mangrove trees.

Natural selection is likely the major force driving $S$. alba salt adaptation to the fluctuating intertidal environment. We lacked comparative transcriptomic data to test how much of the gene expression response to salt treatment is the result of adaptive evolution. However, we did find a number of genes whose evolution at the amino acid level has either accelerated or shows signs of positive selection in the S. alba lineage (Additional file 8: Table S4). Indeed, SA_12151, a member of auxinresponsive family, responds to various abiotic stresses (auxin, high-salinity stresses) in rice [58]. SA_26719 (peroxisomal 3-ketoacyl-CoA thiolase) is a peroxisomeassociated gene. Previous studies have reported that salt stress affects peroxisome enzyme activities and protein expression [59]. Salt-induced expression of peroxisomeassociated genes requires abscisic acid and other signaling pathways [60]. ABA is a stress hormone that plays a central role in a variety of abiotic stress responses. Finally, $S A \_14625$, encoding a hydrolase, is involved in physiologically important processes in plants. It is up- regulated in response to high salinity stress in salttolerant rice [61]. Although our data suggest that these genes are involved in salt tolerance, the mechanisms driving evolution of these up-regulated PSGs must be further confirmed with physiological experiments. It would help us better understand the evolutionary dynamics of salt adaptation.

The most extreme challenge for species living in intertidal zones is the unstable and high salinity due to constant tidal fluctuations. Our analyses of DEGs point to the cellular environment as the possible site of molecular salt adaptation in $S$. alba. Thus, we suggest that the maintenance and regulation of cellular environmental homeostasis are important adaptive processes, contributing to evolutionary innovations.

\section{Conclusions}

We performed comprehensive transcriptome analyses of $S$. alba leaves and roots across salinity conditions. The study demonstrates extensive transcriptional regulation of salt adaptation. Leaves and roots appear to adopt different dynamic gene regulation strategies for salt adaptation in $S$. alba. Most differentially expressed genes in leaves were well adapted to the medium saline condition. Our analyses report several candidate genes (including salt-related genes, TF-encoding genes, and PSGs) and major pathways including sulfur metabolism, flavone and flavonol biosynthesis, nicotinate and nicotinamide metabolism, and cysteine and methionine metabolism, that are involved in adaptation to high-salt environments. We deduce that the 
maintenance and regulation of cellular environmental homeostasis are important adaptive processes. Our study can also serve as a resource for future investigation of adaptive evolution in extreme environments. With additional investigations targeting the methylome and the proteome in the future, the exact mechanisms of salt adaptation in plants can be unveiled.

\section{Methods}

\section{Plant materials and growth conditions}

Eighteen S. alba seedlings (Additional file 9: Figure S5) were collected from the nursery of Dongzhai Harbor National Nature Reserve in Hainan with permission. All samples have been identified by Mr. Cairong Zhong, an officer of Dongzhai Harbor National Nature Reserve Administration. Then they were cultivated in the greenhouse $\left(23^{\circ} \mathrm{C} \sim 35^{\circ} \mathrm{C}, 13.5\right.$-h day-length, a light intensity sufficient to allow normal growth) of Sun Yat-Sen University. The seedlings were transferred to sandy soil and grown using 1/2 Hoagland's solution for 3 weeks to help plants adapt to the new environment. The seedlings were divided into three groups, each group containing two biological replicates. These three experimental groups were irrigated using solutions containing 0, 250, or $500 \mathrm{mM} \mathrm{NaCl}$ for 7 days. In natural condition, S. alba is usually found near the estuary. The rainwater and upstream rivers give it little exposure to normal seawater concentrations. S. alba reaches an optimal growth in 5 to $50 \%$ seawater. Medium saline $(250 \mathrm{mM} \mathrm{NaCl})$, approximately half of the normal seawater salinity, is close to the upper bound for natural S. alba growth [19]. Although $500 \mathrm{mM}$ and $0 \mathrm{mM}$ provide the hyper-saline (stressful) and low-saline conditions, respectively, 0-250 $\mathrm{mM}$ is a range well tolerated by mangroves in nature. In contrast, $250-500 \mathrm{mM}$ is genuinely stressful. The treatment duration was based on our previous study [62].

\section{Sample collection, sequencing, and alignment}

Healthy young leaves and roots of each seedling were sampled after 7 days and immediately frozen in liquid nitrogen and stored at $-80{ }^{\circ} \mathrm{C}$. Three plants from the same group were pooled to minimize variation among individual plants. Total RNA was extracted using the Plant RNA kit (Omega Bio-Tek, Doraville, USA) according to the manufacturer's instructions. For each sample, at least $20 \mu \mathrm{g}$ of total RNA was sent to the Novogene Bioinformatics Technology Co., Ltd. for sequencing using the Illumina HiSeq 2000 platform. Raw sequence reads were first purified by trimming adapter sequences. In order to reduce sequencing error, paired-end lowquality reads were removed by customized scripts if they met the following criteria: i) they comprised more than $5 \%$ unknown (N) bases; ii) comprised more than $20 \%$ bases with quality $<=10$; iii) average quality was under
20. The last base of the filtered reads was also trimmed according to the results of FastQC.

Clean reads from each sample were aligned to the $S$. alba reference genome [10] using TopHat v2.1.1 [63] and Bowtie2 v2.2.9 [64]. We then performed the genome-guided transcriptome assembly and differential transcript expression analyses using Cufflinks v2.2.1 [65]. We reported expression levels as Fragments Per Kilobase of exon model per Million mapped reads (FPKM) values. We then calculated the Pearson's correlation coefficients between all replicates using gene expression data.

\section{Identification of differentially expressed genes and expression pattern analyses}

We identified DEGs from two comparisons: $250 \mathrm{mM}$ $\mathrm{NaCl}$ vs $0 \mathrm{mM} \mathrm{NaCl}$ and $500 \mathrm{mM} \mathrm{NaCl}$ vs $250 \mathrm{mM}$ $\mathrm{NaCl}$. We considered transcripts with $q$-values (FDR-adjusted $P$-values) below $5 \%$ and fold change higher than 2 in either comparison as differentially expressed. We called genes whose expression increased with salt concentration "up-regulated" and transcripts with change in the opposite direction "down-regulated." The remaining genes were denoted as "no significant difference". These DEGs were grouped into eight distinct and representative clusters (LC1 LC8, RC1 RC8) via pairwise comparisons between three expression patterns (upregulated, down-regulated, or non-significant difference) in leaves and roots. To determine which clusters have statistically significant enrichments in the number of genes assigned, we used a permutation test with 10,000 runs. In each permutation we first shuffled all expression quantities obtained under different conditions randomly to destroy any association between the conditions and expression quantities and assigned them to their original gene groups. We then carried out the cluster analysis as for the real data and recorded whether the number of genes assigned to every cluster in the permutation was no smaller than in the actual observation. After 10,000 permutation runs, we estimated the frequency of assigning no fewer genes to a cluster than what is seen in the real expression data, allowing for significance testing.

\section{Gene annotation and ontology enrichment analyses}

We obtained $S$. alba genome annotations and assigned gene ontology (GO) and KEGG orthology (KO) terms to all genes. GO terms were assigned using the Web Gene Ontology Annotation Plotting (WEGO 2.0) [66] and visualized by Cytoscape_v3.7.2 [67]. Transcription factor annotations for $S$. alba and its relatives with genome sequences: Sonneratia caseolaris (true mangrove) [10], Punica granatum (non-mangrove) [68], and Eucalyptus grandis (non-mangrove) [69] were performed using iTAK1.7 [70]. We tested for enrichment of TFs among 
differentially expressed $S$. alba genes using Fisher's exact test. KEGG annotation was carried out to assign DEGs to metabolic pathways. We assigned all up-regulated genes in leaves and roots to KEGG pathways and compared these pathways' gene numbers with the whole genome background. KEGG pathway data were from the $R$ package clusterProfiler [71] which supports downloading the latest KEGG annotations. Pathways with more than three up-regulated genes were processed using Fisher's exact test. Enrichment was declared significant if Benjamini-Hochberg corrected $P$-values fell below $5 \%$. We identified key salt-responsive genes from $S$. alba genome annotations and BLASTP searches of genes upregulated in S. alba against Arabidopsis thaliana genome data (TAIR10, www.arabidopsis.org) with cut-off $e$ value $<10^{-6}$.

\section{Selection analyses}

In order to detect up-regulated genes that might undergo positive selection in $S$. alba, we first identified high-quality orthologs within $S$. alba and its relatives, including Punica granatum, Trapa bispinosa, Lagerstroemia speciosa, Duabanga grandiflora, and Eucalyptus grandis. These species belong to the same order Myrtales (APG IV, www.mobot.org/MOBOT/research/ APweb/welcome.html). The whole genome sequences of Punica granatum, and Eucalyptus grandis were downloaded from phytozome and NCBI [68, 69]. For the more closely related species Trapa bispinosa, Lagerstroemia speciosa, and Duabanga grandiflora, the transcriptomes were sequenced in our previous study [72]. Using the orthologs identified by OrthoMCL [73] as an initial data set, we used the reciprocal BLASTP best-hit method for $S$. alba and five related species. We then individually aligned orthologous proteins using MUSCLE [74] and used the aligned protein sequences to generate codon alignments using PAL2NAL [75]. Alignments shorter than $150 \mathrm{bp}$ after removing sites with ambiguous data were discarded. This process yielded 3936 highquality orthologs within S. alba and its relatives. These codon alignments together with a phylogenetic tree [76] were used for subsequent analyses.

We calculated $\mathrm{Ka} / \mathrm{Ks}$ ratio for each branch of the phylogenetic tree using the "free-ratio" model in the PAML package [77]. All orthologs were concatenated into a single super gene. We used the branch model in the PAML package to identify positively selected genes, setting the S. alba branch as the foreground [78]. We introduced the likelihood comparison between the alternative model allowing the foreground branch to evolve under a different rate and the null model assuming that all branches have been evolving at the same rate for each ortholog set. We also used the branch-site model in PAML by setting model $=2$, NSsites $=2$ [79]. The comparison of likelihoods between the alternative model assuming that at least one site in the foreground has undergone positive selection and the null model that assumes none was used as the test of positive selection. The likelihood ratio test method was the same as for the branch model. Multiple testing was corrected by applying the Benjamini-Hochberg method implemented in the $\mathrm{R}$ function p.adjust. We considered the up-regulated genes with FDR below 5\% as PSGs. Finally, we manually filtered all PSGs with potential errors in their alignments to minimize the false positive rate.

\section{RNA-seq data validation with real-time quantitative PCR}

The qRT-PCR was performed to validate the RNA-seq results for 16 transcripts from 16 distinct clusters $\left(S A_{-}\right.$ 28450 both from LC8 and RC5) in leaves and roots. Gene-specific primers for qRT-PCR were designed using the Primer Premier software and are listed in Additional file 10: Table S5.

First-strand cDNAs were synthesized from $1 \mu \mathrm{g}$ of total RNA using the PrimeScript ${ }^{\mathrm{m} m} \mathrm{RT}$ reagent Kit with gDNA Eraser (TaKaRa). The expression of the $\beta$-actin gene served as the internal control. qRT-PCR was carried out using the Real-Time PCR system on an ABI $7900 \mathrm{HT}$ with the following program: $95^{\circ} \mathrm{C}$ for $30 \mathrm{~s}$ $\left(95^{\circ} \mathrm{C}\right.$ for $5 \mathrm{~s}, 55^{\circ} \mathrm{C}$ for $10 \mathrm{~s}$ and $72^{\circ} \mathrm{C}$ for $\left.15 \mathrm{~s}\right), 40$ cycles. Each sample was analysed with three technical replicates. The relative expression profiles of selected genes were calculated using the $2^{-\triangle \Delta C T}$ method [80]. Correlations between expression profiles of selected genes from RNA-seq and qRT-PCR were estimated using a simple linear regression model using the $l m$ function in $\mathrm{R}$.

\section{Supplementary information}

Supplementary information accompanies this paper at https://doi.org/10. 1186/s12870-020-02395-3.

Additional file 1: Figure S1. Gene expression correlations among all samples. Pearson's correlation plot visualizes the correlation coefficients. Scale bar represents the range of the value displayed. The correlation coefficients between biological replicates in Leaf $0 \mathrm{mM}$, Leaf $250 \mathrm{mM}$, Leaf $500 \mathrm{mM}$, Root $0 \mathrm{mM}$, Root $250 \mathrm{mM}$, and Root $500 \mathrm{mM}$ conditions are 0.92, 0.97, 0.90, 0.97, 0.87, 0.90, respectively.

Additional file 2: Figure S2. Cluster analysis and permutation test of differentially expressed genes (DEGs). Expression profiles of DEGs under different salinity contrasts are shown for eight clusters in leaves and roots. DEGs in leaves are significantly enriched in three clusters (LC8, LC4, LC5), whereas DEGs in roots are significantly enriched in RC1 and RC5. In each cluster, the black line represents the expression level (means of $\log _{10}($ FPKM value +1$)$ ) of all enriched genes, the error bars represent standard deviations. A permutation test was used to evaluate the significance of differences. The clusters with statistically significant difference in the number of DEGs are marked with triple $(P$-value $<0.01)$ asterisks. The observed and expected (only significant clusters) numbers of genes belonging to each cluster are labeled on the top of each cluster.

Additional file 3: Table S1. The GO annotation of DEGs. URG represents up-regulated gene; DRG represents down-regulated gene. The 
numbers in the brackets are percentages of genes with GO ID and those outside the brackets are gene numbers.

Additional file 4: Table S2. Summary of GO terms enriched among genes in co-expression clusters.

Additional file 5: Table S3. The KEGG annotation of up-regulated genes. URG represents up-regulated gene. The numbers in the brackets are percentages of genes with $\mathrm{KO} I \mathrm{D}$ and those outside the brackets are gene or pathway numbers.

Additional file 6: Figure S3. Different expression patterns of transcription factor genes in leaves (A) and roots (B) across salinity contrasts (0,250 and $500 \mathrm{mM} \mathrm{NaCl})$. Various TF families showing differential expression patterns under different conditions are given on the right side of heat map. The middle-upper scale represents FPKM values with z-score normalization.

Additional file 7: Figure S4. Ka/Ks ratio along each branch of the phylogenetic tree. The mangrove lineage $(S$. alba) is colored red, set as the foreground.

Additional file 8: Table S4. PSGs Related to Salt Adaptation in Sonneratia alba.

Additional file 9: Figure S5. The seedlings of S. alba.

Additional file 10: Table S5. Primer sequences for real-time quantitative PCR analysis.

\section{Abbreviations}

AOC: Allene oxide cyclase; DEGs: Differentially expressed genes; FPKM: Fragments Per Kilobase of exon model per Million mapped reads; GO: Gene Ontology; KO: KEGG orthology; NHX: Sodium/hydrogen exchanger; PIP: Plasma membrane intrinsic protein; PSGs: Positively selected genes; qPCR: Real-time quantitative PCR; ROS: Reactive oxygen species; SOS: Salt overly sensitive; TFs: Transcription factors; TIP: Tonoplast intrinsic protein; UV: Ultraviolet; WEGO: Web Gene Ontology Annotation Plotting

\section{Acknowledgements}

We thank Chung-I Wu and Zixiao Guo for insightful comments; and Anthony J. Greenberg for manuscript modifications.

\section{Authors' contributions}

S.S. and Z.H. conceived the study; X.F., S.X., J.L. and Q.C. analysed the data; J.L., Y.Y., H.L. and C.Z. collected materials and performed experiments; X.F., S.X., Z.H. and S.S. wrote the manuscript; all authors read and approved the final manuscript

\section{Funding}

This study was supported by the National Natural Science Foundation of China (31830005 and 31971540); the National Key Research and Development Plan (2017FY100705); Guangdong Basic and Applied Basic Research Foundation (2019A1515010752); the China Postdoctoral Science Foundation (BX201700300 and 2017 M622857); and the Chang Hungta Science Foundation of Sun Yat-sen University. The funding bodies did not involve in the design of the study and collection, analysis, interpretation of data, or writing of the manuscript.

\section{Availability of data and materials}

The RNA-seq data have been deposited in the Genome Sequence Archive database (Accession No. PRJCA001412) and the NCBI Sequence Read Archive database (Accession No. PRJNA615770),

\section{Ethics approval and consent to participate}

Not applicable.

\section{Consent for publication}

Not applicable.

\section{Competing interests}

The authors declare that they have no competing interests.

\section{Author details}

'State Key Laboratory of Biocontrol, Guangdong Key Lab of Plant Resources, Key Laboratory of Biodiversity Dynamics and Conservation of Guangdong Higher Education Institutes, School of Life Sciences, Sun Yat-Sen University, Guangzhou, China. ${ }^{2}$ Hainan Dongzhai Harbor National Nature Reserve Administration, Haikou, China.

Received: 28 October 2019 Accepted: 13 April 2020

Published online: 22 April 2020

\section{References}

1. Giri C, Long J, Abbas S, Murali RM, Qamer FM, Pengra B, et al. Distribution and dynamics of mangrove forests of South Asia. J Environ Manag. 2015; 148:101-11.

2. Ball MC. Ecophysiology of mangroves. Trees. 1988;2:129-42.

3. Parida AK, Jha B. Salt tolerance mechanisms in mangroves: a review. Trees. 2010;24:199-217.

4. Tomlinson PB. The botany of mangroves. 2nd ed. Cambridge: Cambridge University Press; 2016.

5. Huang G-Y, Wang Y-S. Physiological and biochemical responses in the leaves of two mangrove plant seedlings (Kandelia candel and Bruguiera gymnorrhiza) exposed to multiple heavy metals. J Hazard Mater. 2010;182: 848-54.

6. Xu S, He Z, Guo Z, Zhang Z, Wyckoff GJ, Greenberg A, et al. Genome-wide convergence during evolution of mangroves from woody plants. Mol Biol Evol. 2017:34:1008-15.

7. Xu S, He Z, Zhang Z, Guo Z, Guo W, Lyu H, et al. The origin, diversification and adaptation of a major mangrove clade (Rhizophoreae) revealed by whole-genome sequencing. Natl Sci Rev. 2017;4:721-34.

8. Guo Z, Li X, He Z, Yang Y, Wang W, Zhong C, et al. Extremely low genetic diversity across mangrove taxa reflects past sea level changes and hints at poor future responses. Glob Chang Biol. 2018;24:1741-8.

9. Lyu H, He Z, Wu C, Shi S. Convergent adaptive evolution in marginal environments: unloading transposable elements as a common strategy among mangrove genomes. New Phytol. 2018;217:428-38.

10. He Z, Xu S, Zhang Z, Guo W, Lyu H, Zhong C, et al. Convergent adaptation of the genomes of woody plants at the land-sea interface. Natl Sci Rev. 2020. https://doi.org/10.1093/nsr/nwaa027.

11. Cases I, de Lorenzo V, Ouzounis CA. Transcription regulation and environmental adaptation in bacteria. Trends Microbiol. 2003;11:248-53.

12. Seki M, Narusaka M, Ishida J, Nanjo T, Fujita M, Oono Y, et al. Monitoring the expression profiles of 7000 Arabidopsis genes under drought, cold and high-salinity stresses using a full-length cDNA microarray. Plant J. 2002;31: 279-92.

13. Munns R, Tester M. Mechanisms of salinity tolerance. Annu Rev Plant Biol. 2008:59:651-81.

14. Ma T, Wang J, Zhou G, Yue Z, Hu Q, Chen Y, et al. Genomic insights into salt adaptation in a desert poplar. Nat Commun. 2013:4:2797.

15. Ding F, Cui P, Wang Z, Zhang S, Ali S, Xiong L. Genome-wide analysis of alternative splicing of pre-mRNA under salt stress in Arabidopsis. BMC Genomics. 2014;15:431

16. Shankar R, Bhattacharjee A, Jain M. Transcriptome analysis in different rice cultivars provides novel insights into desiccation and salinity stress responses. Sci Rep. 2016;6:23719.

17. Belamkar V, Weeks NT, Bharti AK, Farmer AD, Graham MA, Cannon SB. Comprehensive characterization and RNA-Seq profiling of the HD-zip transcription factor family in soybean (Glycine max) during dehydration and salt stress. BMC Genomics. 2014;15:950.

18. Ji H, Pardo JM, Batelli G, Van Oosten MJ, Bressan RA, Li X. The salt overly sensitive (SOS) pathway: established and emerging roles. Mol Plant. 2013;6: 275-86.

19. Ball MC, Pidsley SM. Growth responses to salinity in relation to distribution of two mangrove species, Sonneratia alba and S. lanceolata, in northern Australia. Funct Ecol. 1995;9:77-85.

20. Yang E, Yi S, Bai F, Niu D, Zhong J, Wu Q, et al. Cloning, characterization and expression pattern analysis of a cytosolic copper/zinc superoxide dismutase (SaCSD1) in a highly salt tolerant mangrove (Sonneratia alba). Int Mol Sci. 2016:17:4

21. Chen S, Zhou R, Huang Y, Zhang M, Yang G, Zhong C, et al. Transcriptome sequencing of a highly salt tolerant mangrove species Sonneratia alba using Illumina platform. Mar Genomics. 2011;4:129-36. 
22. Yang Y, Guo W, Shen X, Li J, Yang S, Chen S, et al. Identification and characterization of evolutionarily conserved alternative splicing events in a mangrove genus Sonneratia. Sci Rep. 2018;8:4425.

23. Zhu J-K. Genetic analysis of plant salt tolerance using Arabidopsis. Plant Physiol. 2000;124:941-8.

24. Hu H, You J, Fang Y, Zhu X, Qi Z, Xiong L. Characterization of transcription factor gene SNAC2 conferring cold and salt tolerance in rice. Plant Mol Biol. 2008;67:169-81.

25. Chen L, Song Y, Li S, Zhang L, Zou C, Yu D. The role of WRKY transcription factors in plant abiotic stresses. Biochim Biophys Acta. 1819;2012:120-8.

26. Lin T, Xu X, Ruan J, Liu S, Wu S, Shao X, et al. Genome analysis of Taraxacum kok-saghyz Rodin provides new insights into rubber biosynthesis. Natl Sci Rev. 2017;5:78-87.

27. Golldack D, Lüking I, Yang O. Plant tolerance to drought and salinity: stress regulating transcription factors and their functional significance in the cellular transcriptional network. Plant Cell Rep. 2011;30:1383-91.

28. Qiu Q, Zhang G, Ma T, Qian W, Wang J, Ye Z, et al. The yak genome and adaptation to life at high altitude. Nat Genet. 2012;44:946-9.

29. He Z, Li X, Yang M, Wang X, Zhong C, Duke NC, et al. Speciation with gene flow via cycles of isolation and migration: insights from multiple mangrove taxa. Natl Sci Rev. 2019;6:275-88.

30. Li J, Gao Z, Zhou L, Li L, Zhang J, Liu Y, et al. Comparative transcriptome analysis reveals $\mathrm{K}+$ transporter gene contributing to salt tolerance in eggplant. BMC Plant Biol. 2019;19:67.

31. He Y, Qi X, Ouzhuluobu LS, Li J, Zhang H, et al. Blunted nitric oxide regulation in Tibetans under high-altitude hypoxia. Natl Sci Rev. 2018;5:51629.

32. Sicilia A, Testa G, Santoro DF, Cosentino SL, Lo Piero AR. RNASeq analysis of giant cane reveals the leaf transcriptome dynamics under long-term salt stress. BMC Plant Biol. 2019:19:355.

33. Liu J-G, Han X, Yang T, Cui W-H, Wu A-M, Fu C-X, et al. Genome-wide transcriptional adaptation to salt stress in Populus. BMC Plant Biol. 2019;19: 367.

34. Furtado BU, Nagy I, Asp T, Tyburski J, Skorupa M, Gołębiewski M, et al. Transcriptome profiling and environmental linkage to salinity across Salicornia europaea vegetation. BMC Plant Biol. 2019;19:427.

35. Gong Q, Li P, Ma S, Indu Rupassara S, Bohnert HJ. Salinity stress adaptation competence in the extremophile Thellungiella halophila in comparison with its relative Arabidopsis thaliana. Plant J. 2005;44:826-39.

36. Olsen $J$, Rouzé $P$, Verhelst B, Lin YC, Bayer T, Collen J, et al. The genome of the seagrass Zostera marina reveals angiosperm adaptation to the sea. Nature. 2016;530:331-5.

37. Muramatsu Y, Harada A, Ohwaki Y, Kasahara Y, Takagi S, Fukuhara T. Salttolerant ATPase activity in the plasma membrane of the marine angiosperm Zostera marina L. Plant Cell Physiol. 2002;43:1137-45.

38. LV X, Yu P, Deng W, Li Y. Transcriptomic analysis reveals the molecular adaptation to $\mathrm{NaCl}$ stress in Zostera marina L. Plant Physiol Biochem. 2018; 130:61-8.

39. Yamada A, Saitoh T, Mimura T, Ozeki Y. Expression of mangrove allene oxide cyclase enhances salt tolerance in Escherichia coli, yeast, and tobacco cells. Plant Cell Physiol. 2002:43:903-10.

40. Zawoznik MS, Ameneiros M, Benavides MP, Vázquez S, Groppa MD. Response to saline stress and aquaporin expression in Azospirilluminoculated barley seedlings. Appl Microbiol Biotechnol. 2011;90:1389-97.

41. TAN W, Lin Q, LIM T, Kumar P, LOH C. Dynamic secretion changes in the salt glands of the mangrove tree species Avicennia officinalis in response to a changing saline environment. Plant Cell Environ. 2013;36:1410-22.

42. Lyu H, Li X, Guo Z, He Z, Shi S. De novo assembly and annotation of the Avicennia officinalis L. transcriptome. Mar Genomics. 2018;39:3-6.

43. Flowers TJ, Garcia A, Koyama M, Yeo AR. Breeding for salt tolerance in crop plants - the role of molecular biology. Acta Physiol Plant. 1997;19:427-33.

44. Geng Y, Wu R, Wee CW, Xie F, Wei X, Chan PMY, et al. A spatio-temporal understanding of growth regulation during the salt stress response in Arabidopsis. Plant Cell. 2013:25:2132-54

45. Anjum NA, Aref IM, Duarte AC, Pereira E, Ahmad I, lqbal M. Glutathione and proline can coordinately make plants withstand the joint attack of metal (loid) and salinity stresses. Front Plant Sci. 2014;5:662.

46. Hernández I, Alegre L, Van Breusegem F, Munné-Bosch S. How relevant are flavonoids as antioxidants in plants? Trends Plant Sci. 2009;14:125-32.

47. Suzuki-Yamamoto M, Mimura T, Ashihara H. Effect of short-term salt stress on the metabolic profiles of pyrimidine, purine and pyridine nucleotides in cultured cells of the mangrove tree, Bruguiera sexangula. Physiol Plant. 2006 128:405-14.

48. Peng J, Li Z, Wen X, Li W, Shi H, Yang L, et al. Salt-induced stabilization of EIN3/EIL1 confers salinity tolerance by deterring ROS accumulation in Arabidopsis. PLoS Genet. 2014;10:e1004664.

49. Jiang $Y$, Deyholos MK. Comprehensive transcriptional profiling of $\mathrm{NaCl}$ stressed Arabidopsis roots reveals novel classes of responsive genes. BMC Plant Biol. 2006;6:25.

50. Gruber V, Blanchet S, Diet A, Zahaf O, Boualem A, Kakar K, et al. Identification of transcription factors involved in root apex responses to salt stress in Medicago truncatula. Mol Gen Genomics. 2009;281:55-66.

51. Miyama M, Tada Y. Transcriptional and physiological study of the response of Burma mangrove (Bruguiera gymnorhiza) to salt and osmotic stress. Plant Mol Biol. 2008;68:119-29

52. Song C-P, Agarwal M, Ohta M, Guo Y, Halfter U, Wang P, et al. Role of an Arabidopsis AP2/EREBP-type transcriptional repressor in abscisic acid and drought stress responses. Plant Cell. 2005:17:2384-96.

53. Jiang J, Ma S, Ye N, Jiang M, Cao J, Zhang J. WRKY transcription factors in plant responses to stresses. J Integr Plant Biol. 2017;59:86-101.

54. Amato A, Cavallini E, Zenoni S, Finezzo L, Begheldo M, Ruperti B, et al. A grapevine TTG2-like WRKY transcription factor is involved in regulating vacuolar transport and flavonoid biosynthesis. Front Plant Sci. 2017;7:1979.

55. Malacarne G, Coller E, Czemmel S, Vrhovsek U, Engelen K, Goremykin V, et al. The grapevine VvibZIPC22 transcription factor is involved in the regulation of flavonoid biosynthesis. J Exp Bot. 2016;67:3509-22.

56. Morishita T, Kojima Y, Maruta T, Nishizawa-Yokoi A, Yabuta Y, Shigeoka S. Arabidopsis NAC transcription factor, ANAC078, regulates flavonoid biosynthesis under high-light. Plant Cell Physiol. 2009;50:2210-22.

57. Xu W, Dubos C, Lepiniec L. Transcriptional control of flavonoid biosynthesis by MYB-bHLH-WDR complexes. Trends Plant Sci. 2015;20:176-85.

58. Jain M, Khurana JP. Transcript profiling reveals diverse roles of auxinresponsive genes during reproductive development and abiotic stress in rice. FEBS J. 2009:276:3148-62

59. Corpas FJ, Gómez M, Hernández JA, Luis A. Metabolism of activated oxygen in peroxisomes from two Pisum sativum $L$. cultivars with different sensitivity to sodium chloride. J Plant Physiol. 1993;141:160-5.

60. Charlton WL, Matsui K, Johnson B, Graham IA, OHME-TAKAGI M, Baker A. Salt-induced expression of peroxisome-associated genes requires components of the ethylene, jasmonate and abscisic acid signalling pathways. Plant Cell Environ. 2005;28:513-24.

61. Opassiri R, Pomthong B, Onkoksoong T, Akiyama T, Esen A, Cairns JRK. Analysis of rice glycosyl hydrolase family 1 and expression of Os4bglu12 $\beta$ glucosidase. BMC Plant Biol. 2006;6:33.

62. Liang S, Fang L, Zhou R, Tang T, Deng S, Dong S, et al. Transcriptional homeostasis of a mangrove species, Ceriops tagal, in saline environments, as revealed by microarray analysis. PLoS One. 2012;7:e36499.

63. Kim D, Pertea G, Trapnell C, Pimentel H, Kelley R, Salzberg SL. TopHat2: accurate alignment of transcriptomes in the presence of insertions, deletions and gene fusions. Genome Biol. 2013;14:R36.

64. Langmead B, Salzberg SL. Fast gapped-read alignment with bowtie 2. Nat Methods. 2012;9:357-9.

65. Trapnell C, Roberts A, Goff L, Pertea G, Kim D, Kelley DR, et al. Differential gene and transcript expression analysis of RNA-seq experiments with TopHat and cufflinks. Nat Protoc. 2012:7:562-78.

66. Ye J, Fang L, Zheng H, Zhang Y, Chen J, Zhang Z, et al. WEGO: a web tool for plotting GO annotations. Nucleic Acids Res. 2006;34:W293-7.

67. Shannon P, Markiel A, Ozier O, Baliga NS, Wang JT, Ramage D, et al. Cytoscape: a software environment for integrated models of biomolecular interaction networks. Genome Res. 2003:13:2498-504.

68. Qin G, Xu C, Ming R, Tang H, Guyot R, Kramer EM, et al. The pomegranate (Punica granatum L.) genome and the genomics of punicalagin biosynthesis. Plant J. 2017;91:1108-28.

69. Myburg AA, Grattapaglia D, Tuskan GA, Hellsten U, Hayes RD, Grimwood J, et al. The genome of Eucalyptus grandis. Nature. 2014;510:356-62.

70. Zheng Y, Jiao C, Sun H, Rosli HG, Pombo MA, Zhang P, et al. iTAK: a program for genome-wide prediction and classification of plant transcription factors, transcriptional regulators, and protein kinases. Mol Plant. 2016:9:1667-70

71. Yu G, Wang L-G, Han Y, He Q-Y. clusterProfiler: an R package for comparing biological themes among gene clusters. OMICS. 2012;16:284-7. 
72. Li J, Yang Y, Yang S, Zhang Z, Chen S, Zhong C, et al. Comparative transcriptome analyses of a mangrove tree Sonneratia caseolaris and its non-mangrove relatives, Trapa bispinosa and Duabanga grandiflora. Mar Genomics. 2017:31:13-5.

73. Li L, Stoeckert CJ, Roos DS. OrthoMCL: identification of ortholog groups for eukaryotic genomes. Genome Res. 2003;13:2178-89.

74. Edgar RC. MUSCLE: multiple sequence alignment with high accuracy and high throughput. Nucleic Acids Res. 2004;32:1792-7.

75. Suyama M, Torrents D, Bork P. PAL2NAL: robust conversion of protein sequence alignments into the corresponding codon alignments. Nucleic Acids Res. 2006;34:W609-12.

76. Huang Y, Shi S. Phylogenetics of Lythraceae sensu lato: a preliminary analysis based on chloroplast rbcL gene, psaA-ycf3 spacer, and nuclear rDNA internal transcribed spacer (ITS) sequences. Int J Plant Sci. 2002;163: 215-25.

77. Yang Z. PAML 4: phylogenetic analysis by maximum likelihood. Mol Biol Evol. 2007:24:1586-91.

78. Yang Z. Likelihood ratio tests for detecting positive selection and application to primate lysozyme evolution. Mol Biol Evol. 1998;15:568-73.

79. Yang Z, Nielsent R. Codon-substitution models for detecting molecular adaptation at individual sites along specific lineages. Mol Biol Evol. 2002;19: 908-17.

80. Livak KJ, Schmittgen TD. Analysis of relative gene expression data using real-time quantitative PCR and the 2(-Delta Delta C(T)) method. Methods. 2001;25:402-8.

\section{Publisher's Note}

Springer Nature remains neutral with regard to jurisdictional claims in published maps and institutional affiliations.

Ready to submit your research? Choose BMC and benefit from:

- fast, convenient online submission

- thorough peer review by experienced researchers in your field

- rapid publication on acceptance

- support for research data, including large and complex data types

- gold Open Access which fosters wider collaboration and increased citations

- maximum visibility for your research: over $100 \mathrm{M}$ website views per year

At BMC, research is always in progress.

Learn more biomedcentral.com/submissions 